\title{
SURVIVAL ANALYSIS AND RISK FACTORS FOR DEATH IN TUBERCULOSIS PATIENTS ON DIRECTLY OBSERVED TREATMENT-SHORT COURSE
}

\author{
GEETA PARDESHI
}

\section{ABSTRACT}

BACKGROUND: Tuberculosis is a disease with a high case fatality of $4.65 \%$. OBJECTIVES: To describe the survival pattern of patients on Directly Observed Treatment-Short course (DOTS) according to categories, age and sex of patients. SETINGS: Tuberculosis unit (TU) at District Tuberculosis Centre (DTC), Yavatmal, India DESIGN: Retrospective cohort study. MATERAILS AND METHODS: Data of patients registered for DOTS in the year 2004 were collected from the tuberculosis register. STATISTICAL ANALYSIS: Kaplan Meier plots and log rank tests to assess the survival pattern. Cox proportional hazards model for multivariate analysis. RESULTS: A total of 716 patients were registered at the TU. The survival rates by the end of the intensive phase were $96 \%, 93 \%$ and $99 \%$ in categories I, II and III of DOTS, respectively. The cumulative survival rates were $93 \%, 88 \%$ and $96 \%$ in the three DOTS categories, respectively. There was a significant difference in the survival curves amongst the three DOTS categories (log rank statistic $=7.26$, d.f.. $=2, P=0$ 0.02) and amongst the different age groups [ $\log$ rank statistic $=8.78$, d.f. $=3, P=0.012$ ). There was no difference in the survival curves of male and female patients (log rank statistic $=0.05$, d.f. $=1, P=0.80$ ) and according to type of disease (log rank statistic $=5.63$, d.f. $=2, P=0.05$ ). On Cox proportional hazard analysis, age groups of $\mathbf{4 0}$ to $\mathbf{6 0}$ years [adjusted hazard ratio $=7.81$ (1.002-60.87)] and above 60 years [adjusted hazard ratio $=21.54$ (2.57-180.32)] were identified as significant risk factors for death. CONCLUSIONS: Age above 40 years is a significant risk factor for death in patients of tuberculosis. There was a significant difference in survival curves of the three DOTS categories and age groups.

Key words: Tuberculosis, death, directly observed treatment-short course, revised National Tuberculosis Control Programme

DOI: $10.4103 / 0019-5359.53163$

\section{INTRODUCTION}

In India, which accounts for $30 \%$ of the global

Department of PSM, Dr. Shankarrao Chavan

Government Medical College, Nanded, India

Correspondence:

Dr. Geeta Pardeshi,

SnehaNiwas, Workshop road, Nanded, Maharashtra, India

E-mail: geetashrikar@yahoo.com burden of tuberculosis (TB), the Directly Observed Treatment-Short course (DOTS) program has undergone massive expansion as treatment success rate has doubled and death rate has fallen. ${ }^{[1]}$ With an approximate 18 additional lives saved per 100 patients treated under the Revised National Tuberculosis Control Programme (RNTCP), the program has substantially reduced deaths amongst patients 
treated and saved an estimated over 1.4 million additional lives since its inception. ${ }^{[2]}$

Reducing the morbidity and mortality due to tuberculosis is one of the major goals of RNTCP. The death rate amongst the new smear-positive patients has been reduced to less than $5 \% .{ }^{[3]}$ Yet amongst the infectious diseases, TB continues to be a disease with a high case fatality, viz. $4.27 \% .{ }^{[4]}$

Studying the survival patterns in this scenario will help in identifying the risk factors for mortality in these patients and planning effective interventions to further reduce death rates.

The aim of the study is to describe the survival probability with respect to the DOTS category, type of disease, age and sex of the patient.

\section{MATERIALS AND METHODS}

RNTCP was initiated in Yavatmal district in August 2002. By the end of the year 2004, the entire district was covered under DOTS. The district has an annualized total case detection rate of 134 per 100,000 of the population and a cure rate of $85 \%$.

A retrospective cohort study was conducted in which all patients registered for DOTS at the tuberculosis unit in the District Tuberculosis Centre, Yavatmal, from $1^{\text {st }}$ January 2004 to $31^{\text {st }}$ December 2004 were included in the study cohort. The data regarding age, sex, DOTS category, treatment outcome and time of outcome of treatment were collected from the tuberculosis register at the DTC. The entire process of data retrieval and data entry was done by the investigator. As secondary data was collected and the study did not have direct patient involvement, ethical clearance was not needed.

Kaplan Meier analysis was used to study survival pattern, in which the probability of survival in each month after treatment initiation was calculated followed by calculation of cumulative probability of survival by the end of that particular month. The group variables studied included category of DOTS, age and sex of the patients. The end point studied was death. The time of death was ascertained by calculating the difference between the date of initiation and date of outcome. The difference was divided by 30 to determine the month in which the event occurred. For example, if the difference was 100 days, it was divided by 30 to get the figure 3.33 , the inference being that the outcome occurred in the fourth month. The events which were censored were default, treatment completion, cure, failure and transfer.

The Kaplan Meier curve was drawn to arrive at the overall estimate of patients surviving at the end of each month. The difference in the survival patterns over time between different groups was studied using the log rank test. The Cox proportional hazards model was used for multivariate analysis to identify the risk factors for death.

\section{RESULTS}

A total of 716 patients were registered at the DTC during the year 2004. Of these, 275 belonged to category I, 106 to category II and 335 to category III. Amongst the 235 new smear-positive cases, the treatment 
success rate was $86.06 \%$, default rate was $6.3 \%$, death rate was $4.7 \%$ and failure rate was $2.94 \%$.

The median time of death was 2 months for majority of the groups. The death rate in category I was $6.8 \%$; in category II, $10.38 \%$; and in category III, $3.28 \%$. The death rate was more than $10 \%$ in category II (retreatment group) and in the age group 'more than 60 years' [Table 1]. Out of the 19 deaths in category I, 11 occurred in smear-positive cases, 6 in smear-negative cases and 2 in extra-pulmonary tuberculosis cases. All the 11 deaths in category III occurred in smearnegative tuberculosis cases.

The Kaplan Meier analysis of the data [Table 2] showed that in category I the probability of survival at the end of the intensive phase was $96 \%$. The probability of survival at the end of 6 months and till the time all patients were censored remained at $96 \%$. In category II the probability of survival at the end of the intensive phase was $93 \%$; and by the end of the $10^{\text {th }}$ month, by which time all patients were censored, it was $88 \%$. In category III, probability of survival was $99 \%$ at the end of the intensive phase and $96 \%$ by the time all patients were censored. Of the total deaths, $57.89 \%(11 / 19)$ in category I, $63.63 \%(7 / 11)$ in category II and $36.36 \%(4 / 11)$ in category III occurred at the end of the intensive phase.

These findings are represented in the Kaplan Meier plot in Figure 1, which describes the survival curves of the three DOTS categories.

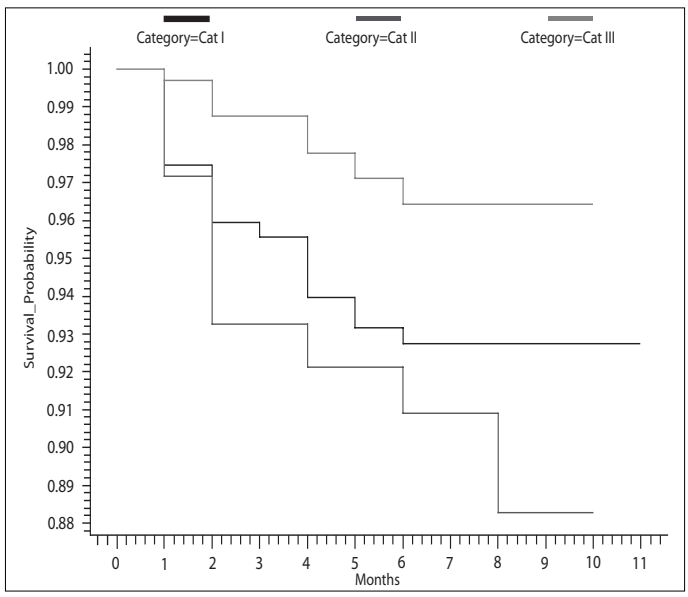

Figure 1: Kaplan Meier plot of survival probabilities according to DOTS categories

Table 1: Death rates and median time of death in various groups

\begin{tabular}{|c|c|c|c|}
\hline Variable & Deaths $(N)$ & Death rate (\%) & $\begin{array}{c}\text { Median time of death (month) } \\
\text { [Interquartile range] }\end{array}$ \\
\hline \multicolumn{4}{|l|}{ Category } \\
\hline Category I $(n=275)$ & 19 & 6.91 & $2[1-4]$ \\
\hline Category II (106) & 11 & 10.38 & $2[1-6]$ \\
\hline Category III (335) & 11 & 3.28 & $4[2-5]$ \\
\hline \multicolumn{4}{|l|}{ Sex } \\
\hline Male (448) & 26 & 5.80 & $3[2-5]$ \\
\hline Female $(n=268)$ & 15 & 5.59 & $2[1-4]$ \\
\hline \multicolumn{4}{|l|}{ Age group } \\
\hline Age $\leq 20$ years $(n=129)$ & 1 & 0.77 & $8[\mathrm{na}]^{*}$ \\
\hline Age 21 to 40 years $(n=384)$ & 23 & 5.98 & $2[1-4]$ \\
\hline Age 41 to 60 years $(n=168)$ & 11 & 6.55 & $2[2-4]$ \\
\hline Age $>60$ years $(n=35)$ & 6 & 17.14 & $2[2-4]$ \\
\hline \multicolumn{4}{|l|}{ Type of disease } \\
\hline New Pulmonary (476) & 30 & 5.67 & $4[1-5]$ \\
\hline Extra-pulmonary(134) & 2 & 2.23 & $2[\mathrm{na}]^{\star}$ \\
\hline Re-treatment (106) & 11 & 10.37 & $2[1-6]$ \\
\hline
\end{tabular}

*na $=$ not applicable 
Table 2: Kaplan Meier analysis of deaths according to the Directly Observed Treatment-Short categories

\begin{tabular}{|c|c|c|c|c|c|c|c|}
\hline Category & Months & $\begin{array}{c}\text { Number of } \\
\text { patients initiated } \\
\text { on treatment }\end{array}$ & $\begin{array}{l}\text { No. of } \\
\text { deaths }\end{array}$ & $\begin{array}{c}\text { No. } \\
\text { Censored }\end{array}$ & $\begin{array}{l}\text { Probability of } \\
\text { death in } \\
\text { the month }\end{array}$ & $\begin{array}{l}\text { Probability of } \\
\text { survival in } \\
\text { the month }\end{array}$ & $\begin{array}{l}\text { Probability of } \\
\text { survival up to the } \\
\text { end of the month }\end{array}$ \\
\hline \multirow[t]{7}{*}{ Category I } & 1 & 275 & 7 & 9 & 0.03 & 0.97 & 0.97 \\
\hline & 2 & 259 & 4 & 9 & 0.02 & 0.98 & 0.96 \\
\hline & 3 & 246 & 1 & 5 & 0.00 & 1 & 0.96 \\
\hline & 4 & 240 & 4 & 6 & 0.02 & 0.98 & 0.94 \\
\hline & 5 & 230 & 2 & 3 & 0.01 & 0.99 & 0.93 \\
\hline & 6 & 225 & 1 & 98 & 0.00 & 1 & 0.93 \\
\hline & $\geq 7$ & 126 & 0 & 126 & 0.00 & 1 & 0.93 \\
\hline \multirow{9}{*}{ Category II } & 1 & 106 & 3 & 4 & 0.03 & 0.97 & 0.97 \\
\hline & 2 & 99 & 4 & 8 & 0.04 & 0.96 & 0.93 \\
\hline & 3 & 87 & 0 & 4 & 0.00 & 1.00 & 0.93 \\
\hline & 4 & 83 & 1 & 3 & 0.01 & 0.99 & 0.92 \\
\hline & 5 & 79 & 0 & 3 & 0.00 & 1.00 & 0.92 \\
\hline & 6 & 76 & 1 & 2 & 0.01 & 0.99 & 0.91 \\
\hline & 7 & 73 & 0 & 4 & 0.00 & 1.00 & 0.91 \\
\hline & 8 & 69 & 2 & 45 & 0.03 & 0.97 & 0.88 \\
\hline & $\geq 9$ & 22 & 0 & 22 & 0.00 & 1.00 & 0.88 \\
\hline \multirow[t]{7}{*}{ Category III } & 1 & 335 & 1 & 15 & 0.003 & 0.997 & 1.00 \\
\hline & 2 & 319 & 3 & 8 & 0.009 & 0.991 & 0.99 \\
\hline & 3 & 308 & 0 & 7 & 0.000 & 1.000 & 0.99 \\
\hline & 4 & 301 & 3 & 4 & 0.010 & 0.990 & 0.98 \\
\hline & 5 & 294 & 2 & 5 & 0.007 & 0.993 & 0.97 \\
\hline & 6 & 287 & 2 & 135 & 0.007 & 0.993 & 0.96 \\
\hline & $\geq 7$ & 150 & 0 & 150 & 0.000 & 1.000 & 0.96 \\
\hline
\end{tabular}

There was a significant difference in the survival curves for the three DOTS categories (log rank statistic $=7.26$, d.f. $=2, P=0.02$ ). $\mathrm{A}$ high proportion of deaths in category II and I occurred in the intensive phase.

A similar type of analysis was done for sex, age and type of disease.

There was no significant difference in the survival curves between the male and female patients (log rank statistic $=0.05$, d.f. $=1$, $P=0.80$ ). Survival rates at the end of intensive phase in males was $97 \%$; and in females, $96 \%$. The cumulative survival rate at the end of the treatment period was $92 \%$ in males and $93 \%$ in females.

The difference in survival curves amongst the four age groups studied was statistically significant $(\log$ rank statistic $=14.08$, d.f. $=3, P=$
0.002). Survival rate at the end of the intensive phase was $100 \%$ in the patients in the age group 'up to 20 years,' while it was $96 \%$, 97\% and $91 \%$ in the patients in the age groups ' 21 to 40 years,' ' 41 to 60 years' and 'more than 60 years,' respectively. The cumulative survival rates were $95 \%, 94 \%, 93 \%$ and $86 \%$ in the four age groups, respectively.

There was no significant difference in the survival curves of the different types of the disease $(\log$ rank statistic $=5.63$, d.f. $=2, P=$ 0.05 ). The survival rates at the end of the intensive phase were $97 \%, 98 \%$ and $93 \%$ in the new pulmonary, extra-pulmonary and retreatment groups, respectively. The cumulative survival rates at the end of the treatment period were $94 \%, 98 \%$ and $88 \%$ in these three groups, respectively.

On multivariate analysis [Table 3], age was 
Table 3: Cox proportional hazard analysis of deaths in patients on DOTS

\begin{tabular}{|c|c|c|c|c|c|c|}
\hline \multirow[t]{2}{*}{ Variable } & \multicolumn{3}{|c|}{ Univariate analysis } & \multicolumn{3}{|c|}{ Multivariate analysis } \\
\hline & $\begin{array}{c}\text { Hazard ratio } \\
(95 \% \mathrm{Cl})\end{array}$ & Z stat & $P{ }^{*}$ Value & $\begin{array}{c}\text { Adjusted Hazard } \\
\text { ratio }(95 \% \mathrm{Cl})\end{array}$ & Z stat & $P$ *value \\
\hline Category II vs. Category I & $1.40(0.65-2.99)$ & 0.86 & 0.38 & $1.86(0.001-2527.55)$ & 0.16 & 0.86 \\
\hline Category III vs. Category I & $0.47(0.22-0.99)$ & -1.98 & 0.04 & $0.56(0.25-1.25)$ & -1.4 & 0.16 \\
\hline 21 to 40 yrs vs. $\leq 20$ yrs & $8.13(0.09-60.20)$ & 2.05 & 0.04 & $7.17(0.96-53.28)$ & 1.92 & 0.05 \\
\hline 41 to 60 yrs vs. $\leq 20$ yrs & $9.16(0.18-70.95)$ & 2.12 & 0.03 & $7.81(1.002-60.87)$ & 1.96 & 0.04 \\
\hline$>60$ yrs vs. $\leq 20$ yrs & $22.79(2.74-189.23)$ & 2.89 & 0.003 & $21.54(2.57-180.32)$ & 2.83 & 0.004 \\
\hline Male vs. female & $1.08(0.57-2.04)$ & 0.24 & 0.80 & $0.87(0.46-1.67)$ & -0.39 & 0.69 \\
\hline Extra-pulmonary vs. new pulmonary & $0.40(0.12-1.31)$ & -1.50 & 0.132 & $0.61(0.71-2.20)$ & -0.74 & 0.45 \\
\hline Re-treatment cases vs. new pulmonary & $1.69(0.82-3.49)$ & 1.42 & 0.153 & $0.75(0.0006-1010.78)$ & -0.07 & 0.93 \\
\hline
\end{tabular}

identified as a risk factor for mortality. The patients aged 41 to 60 years were 7.8 times more at risk of death as compared to patients aged less than 20 years, and patients aged above 60 years were 21.54 times more at risk of death as compared to the patients aged less than 20 years.

\section{DISCUSSION}

The survival rates in this study were found to be $93 \%, 88 \%$ and $96 \%$ in categories I, II and III, respectively. The survival rates reported in another study were $96 \%, 94 \%$ and $97 \%$ in categories I, II and III, respectively. ${ }^{[5]}$

Age has been identified as an important risk factor for death in tuberculosis patients. Higher death rates have been noted in the elderly patients. ${ }^{[6-9]}$ Apart from the increased physiological risk of death, the vague symptoms in the elderly, diagnostic problems and concomitant illness could be some of the contributing factors for the increased death rate in the elderly. ${ }^{[7,10]}$ Concomitant diseases like cardiovascular diseases, COPD, diabetes mellitus and malignancy have been found to be frequently present in the older patients with tuberculosis. ${ }^{[10,11]}$ Screening the patients for these diseases and managing them appropriately will be important.

In this study, out of the total 41 deaths in patients of tuberculosis, 11 deaths occurred in smear-positive patients; and remaining 30 deaths, in other groups of patients. In another study conducted in the state of Delhi, mortality due to tuberculosis was considerably reduced among new sputum-positive cases with the implementation of RNTCP. However, mortality among smear-negative and new extra-pulmonary and re-treatment cases did not show any significant decline. ${ }^{[12]}$ This is presumably because the emphasis during phase I of RNTCP had been mainly on new smear-positive cases. As these goals are achieved, it is necessary to look at the treatment outcomes in other groups of patients and study the underlying causes of death and effect of HIV co-infection in these groups. In a study on extra-pulmonary tuberculosis it was noted that $47 \%$ patients had co-morbidities, and death was related to tuberculosis in $48 \%$ of the patients. ${ }^{[13]}$ In a study on extra-pulmonary tuberculosis, HIV co-infection was associated with high mortality rates. ${ }^{[14]}$ In another study HIV infection was found to significantly increase the risk of death in smear- negative tuberculosis. ${ }^{[15]}$

As secondary data was utilized for our study, 
a number of other factors such as addictions, co-morbidities, HIV status could not be studied.

A lower survival rate at the end of the intensive phase was noted in re-treatment cases (category II) and in patients with age above 60 years. More than half of the total deaths in categories II and I occur in the intensive phase of treatment. Category II includes patients receiving re-treatment after default, failure or relapse. Incomplete treatment is a known risk factor for mortality in tuberculosis patients. ${ }^{[16,17]}$ It would be interesting to study whether old age and incomplete treatment, which are known risk factors for mortality in tuberculosis, also result in early deaths during the course of treatment.

It is important to study the characteristics of patients who die within two months of treatment and those who die later in the continuation phase. This will help in planning effective interventions to prevent deaths due to tuberculosis.

\section{REFERENCES}

1. DOTS prevents TB deaths in India. India, Tuberculosis [cited on 2008 Apr 24]. Available from: http://www.who.int/inf-new/tuber3.htm

2. Tuberculosis, Communicable diseases and disease surveillance. Core programme clusters [cited on 2008 Apr 24]. Available from: http://www. whoindia.org/en/Section3/Section123.htm.

3. Central TB division .I am stopping TB.TB India 2009 RNTCP status report. DGHS, Ministry of Health and Family Welfare, Govt of India. 2009,10 .

4. Central Bureau of Health Information. National health profile 2008.DGHS, Ministry of Health and Family Welfare, Govt of India.2009, 57.

5. Vasantha M, Gopi PG, Subramani R. Survival of tuberculosis patients treated under DOTS in a rural Tuberculosis Unit (TU), south India. Indian J Tuberc 2008;55:64-9.

6. Gaur SN, Dhingra VK, Rajpal S, Aggarwal JR, Meghna. Tuberculosis in the elderly and their treatment outcome under DOTS. Indian J Tuberc 2004;51:83-7.

7. Sood R. The problem of geriatric tuberculosis. J Acad Clin Med 2000;5:156-62.

8. Pardeshi G, Deshmukh D. Disease characteristics and treatment outcome in elderly tuberculosis patients on DOTS. Indian J Community Med 2007;32:292-4.

9. Mukherjee A, Saha I, Paul B. Tuberculosis in Patients Below and Above 60 years and Their Treatment Outcome Under RNTCP: A study in Rural West Bengal, India. J Indian Acad Geriatr 2008:4:60-3.

10. Perez-Guzman C, Vargas MH, Torres-Cruz $A$, Villarreal-Velarde $H$. Does aging modify Pulmonary Tuberculosis? A meta-analytical review. Chest 1999;116:961-7.

11. Dewan PK, Arguin PM, Kiryanova H, Kondroshova NV, Khorosheva TM, Laserson K, et al. Risk factors for death during tuberculosis treatment in Orel, Russia. Int J Tuberc Lung Dis 2004;8:598602.

12. DhingraVK, Aggarwal N, Chandra S, Vashist RP. Tuberculosis mortality trends in Delhi after implementation of RNTCP. Indian J Tuberc 2009;56:77-81.

13. Bukhary ZA, Alrajhi AA. Extrapulmonary tuberculosis, clinical presentation and outcome. Saudi Med J $2004 ; 25: 881-5$.

14. Kourbatova EV, Leonard MK, Romero J, Kraft C, Rio C, Blumberg HM. Risk factors for mortality among patients with extrapulmonary tuberculosis at an academic inner-city hospital in the US. Eur J Epidemiol 2006;21:715-21.

15. Hargreaves NJ, Kadzakumanja O, Whitty CJ, Salaniponi FM, Harries AD, Squire SB. 'Smearnegative' pulmonary tuberculosis in a DOTS programme: Poor outcomes in an area of high 
HIV seroprevalence. Int J Tuberc Lung Dis 2001;5:847-54.

16. Kolappan C, Subramani R, Kumaraswami V, Santha T, Narayanan PR. Excess mortality and risk factors for mortality among a cohort of TB patients from rural south India. Int J Tuberc Lung Dis 2008;12:81-6.
17. Kolappan C, Subramani R, Karunakaran K, Narayanan PR. Mortality of tuberculosis patients in Chennai, India. Bull World Health Organ 2006;4:555-60.

Source of Support: Nil, Conflict of Interest: None declared.

\section{Author Help: Reference checking facility}

The manuscript system (www.journalonw eb.com) allows the authors to check and verify the accuracy and style of references. The tool checks the references with PubM ed as per a predefined style. Authors are encouraged to use this facility, before submitting articles to the journal.

- The style as well as bibliographic elements should be $100 \%$ accurate, to help get the references verified from the system. Even a single spelling error or addition of issue number/month of publication will lead to an error when verifying the reference.

- $\quad$ Example of a correct style

Sheahan P, O'leary G, Lee G, Fitzgibbon J . Cystic cervical metastases: Incidence and diagnosis using fine needle aspiration biopsy. Otolaryngol Head Neck Surg 2002;127:294-8.

- $\quad$ Only the references from journals indexed in PubM ed will be checked.

- $\quad$ Enter each reference in new line, without a serial number.

- Add up to a maximum of 15 references at a time.

- If the reference is correct for its bibliographic elements and punctuations, it will be shown as CORRECT and a link to the correct article in PubM ed will be given.

- If any of the bibliographic elements are missing, incorrect or extra (such as issue number), it will be shown as INCORRECT and link to possible articles in PubM ed will be given. 